\title{
Clinical Gastroenterology and Gastrointestinal Endoscopy Practices during the Coronavirus Disease 2019 Pandemic in Indonesia: An Online Nationwide Survey
}

\author{
Ahmad Fariz Malvi Zamzam Zein', Rabbinu Rangga Pribadi', Uswatun Khasanah ${ }^{3}$, Muhammad Begawan Bestari ${ }^{4}$ and Ari Fahrial \\ Syam ${ }^{2}$ \\ ${ }^{1}$ Department of Internal Medicine, Faculty of Medicine, Universitas Swadaya Gunung Jati-Waled General Hospital, Cirebon, ${ }^{2}$ Division of \\ Gastroenterology, Department of Internal Medicine, Faculty of Medicine, Universitas Indonesia-Cipto Mangunkusumo National General \\ Hospital, Jakarta, ${ }^{3}$ Department of Biostatistics and Epidemiology, Faculty of Medicine, Universitas Swadaya Gunung Jati, Cirebon, \\ ${ }^{4}$ Division of Gastroenterohepatology, Department of Internal Medicine, Faculty of Medicine, Universitas Padjadjaran-Hasan Sadikin \\ Hospital, Bandung, Indonesia
}

Background/Aims: The coronavirus disease 2019 (COVID-19) pandemic has necessitated modifications to allow the safe practice of clinical gastroenterology and gastrointestinal endoscopy. This study aimed to investigate the characteristics of clinical gastroenterology and gastrointestinal endoscopy practices during the COVID-19 pandemic in Indonesia.

Methods: This cross-sectional study enrolled physician members of the Indonesian Society for Digestive Endoscopy. We used an online self-administered questionnaire disseminated via social media. The 32-item survey determined the baseline characteristics of the participants, characteristics of clinical gastroenterology and gastrointestinal endoscopy practices, involvement of the physicians in the management of COVID-19, and overall impact of the pandemic on practice. All collected data were analyzed using descriptive statistics.

Results: The 200 participants in this study had a median age of 50 (34-76) years. Modifications in clinical gastroenterology practice were frequently reported in the outpatient (95.5\%) and inpatient (100\%) settings. All participants reported changes in the gastrointestinal endoscopy practice patterns. Of the participants, $86.0 \%$ were working in high-risk zones, and several of them reported inadequate protective personal equipment (34.0\%). The median overall impact score of the pandemic on practice was $9(2-10)$.

Conclusions: Physicians practicing clinical gastroenterology and gastrointestinal endoscopy in Indonesia work in high-risk settings. Modifications in clinical gastroenterology and gastrointestinal endoscopy practices are prevalent during the COVID-19 pandemic. Clin Endosc 2021;54:348-355

Key Words: Clinical; COVID-19; Gastroenterology; Gastrointestinal endoscopy; Practice

\section{INTRODUCTION}

Coronavirus disease 2019 (COVID-19) is a rapidly evolving

Received: August 6, 2020 Revised: October 28, 2020

Accepted: November 29, 2020

Correspondence: Ahmad Fariz Malvi Zamzam Zein

Department of Internal Medicine, Faculty of Medicine, Universitas Swadaya Gunung Jati-Waled General Hospital, Jalan Taman Pemuda 2 Kompleks Stadion Bima, Kesambi, Kota Cirebon, West Java 45132, Indonesia

Tel: +62-231-483928, Fax: +62-231-488923, E-mail: fariz_zein_dr@yahoo.com ORCID: https://orcid.org/0000-0001-7821-3813

(c) This is an Open Access article distributed under the terms of the Creative Commons Attribution Non-Commercial License (http://creativecommons.org/ licenses/by-nc/3.0) which permits unrestricted non-commercial use, distribution, and reproduction in any medium, provided the original work is properly cited. global challenge. It has been declared a worldwide pandemic, posing a severe threat to public safety and health. ${ }^{1}$ Health-care systems face the challenge of providing care under the emerging burden of increasing number of patients with COVID-19 and communities at a high risk of the disease. Furthermore, health-care services, health-care facilities, and health-care providers are engaged in activities with a high risk of transmission. ${ }^{2}$

COVID-19, caused by severe acute respiratory syndrome coronavirus 2 (SARS-CoV-2) infection, is a human-to-human transmitted disease that spreads mainly through droplets, close contact, and likely airborne transmission. Furthermore, studies have reported that SARS-CoV-2 ribonucleic acid has 
been detected in feces, raising the possibility of fecal-oral transmission. Aerosol-generating procedures (AGPs) are also a contributing factor in the transmission of COVID-19. The routes of transmission need to be carefully considered when providing health-care services, including in clinical gastroenterology (CGE) and gastrointestinal endoscopy (GIE) practices. $^{1,3-7}$

Some guidelines have proposed modifications to CGE and GIE practices, including the development of risk assessments and stratification of patients, standard operating procedures for COVID-19 prevention and control, appropriate selection and use of protective personal equipment (PPE), and restriction of indications. ${ }^{3,5,6,8-10}$ The Indonesian Society for Digestive Endoscopy (ISDE) released guidelines with similar recommendations to enable physicians to safely practice CGE and GIE. There has been a notable decline ( $>50 \%)$ in GIE procedures during the COVID-19 pandemic (March-June 2020) compared with the pre-pandemic period (November 2019February 2020) in the Center of Digestive Endoscopy in Cipto Mangunkusumo National General Hospital, Jakarta, Indonesia. However, to our knowledge, the extent of the impact of the COVID-19 pandemic on CGE and GIE practices in Indonesia has not been investigated. This study aimed to investigate the characteristics of CGE and GIE practices in Indonesia during the COVID-19 pandemic.

\section{MATERIALS AND METHODS}

\section{Study design and study sample}

We conducted a cross-sectional study using an online survey instrument to gather responses from physicians practicing CGE and GIE in Indonesia. This study was conducted from May 11 to June 30, 2020. We recruited all physician members of the ISDE. A purposive sampling method was used in this study.

\section{Study tool}

The instrument used in this study was a 32-item survey questionnaire for determining the baseline characteristics of the participants, modifications to CGE and GIE practices, physician risk, involvement of the physicians in the management of COVID-19, and impact of the pandemic on professional practice. The baseline characteristics included demographic information (sex, age), workplace of GIE procedures, and qualification (competence, work experience in years, learning source).

CGE practice modifications were identified according to change in outpatient settings, change in inpatient settings, and difficulty in performing clinical research. The GIE practice modifications were evaluated according to the performance of GIE, modifications in GIE practice patterns, change in the indications of GIE, availability of PPE, adequacy of PPE usage, and modification in staff in the endoscopy unit. Adequate PPE comprised an N95 mask, goggles or a face shield, a head cap, gloves, and a surgical gown. Modification in staff in the endoscopy unit referred to any alterations in staff members, type of staff, or work shifts. Physician risk identification consisted of identifying the risk according to symptoms, contact history, travel history, working at/living in a high-risk zone, self-diagnostic tests, and performing GIE on suspected or confirmed COVID-19 patients. Involvement in the management of COVID-19 constituted serving a role in a physician team for suspected or confirmed COVID-19 patients or in a taskforce for COVID-19. The impact of the pandemic on professional practice was assessed using one Likert item question weighted $1-10$, according to the physicians' subjective impressions.

\section{Data collection and statistical analysis}

The formulated questionnaire was administered through the digital platform Google Forms. The Google Forms link was disseminated through messenger applications such as WhatsApp, Telegram, and Line to groups related to the ISDE membership communication network. The participants' responses were initially collected as Google Forms data, which were subsequently extracted into a spreadsheet file and exported to Microsoft Excel for cleaning and coding. The cleaned data were exported to IBM SPSS Statistics 23.0 (IBM Corp., Armonk, NY, USA).

Numerical data are summarized as means and standard deviations or medians and ranges, as appropriate. Categorical data are summarized as frequencies and proportions.

\section{Ethical considerations}

This study was approved by the Medical Research Ethics Committee at the Faculty of Medicine, Universitas Swadaya Gunung Jati, Cirebon, Jawa Barat, Indonesia (registration no. 46/EC/FKUGJ/V/2020). The submission of the answered survey questionnaire constituted consent to participate in this study. Privacy and confidentiality were ensured.

\section{RESULTS}

\section{Baseline characteristics of the participants}

Of the 569 registered ISDE members, 200 physicians were recruited for this study. The participants were from all 22 ISDE branches (Table 1). Their baseline characteristics are shown in 
Table 2. The participants had a median age of 50.00 (34-76) years and showed a male predominance (74.0\%).

The professional background of the participants was also evaluated. Internal medicine specialists with competence in basic GIE comprised the majority of the participants in this study. Almost all participants (97.5\%) adhered to national guidelines and were members of national professional associations. The most frequent workplace for performing GIE was a private non-teaching hospital.

\section{Modifications to clinical gastroenterology practice}

The modifications to CGE practice patterns are shown in Table 3. The changes in the outpatient setting included reductions in working hours (70.0\%), number of attended patients

Table 1. Distribution of Participants Based on Indonesian Society for Digestive Endoscopy Branches

\begin{tabular}{|c|c|c|c|}
\hline No. & ISDE regional branch & $\begin{array}{c}\text { Participants per } \\
\text { branch }(n)\end{array}$ & $\begin{array}{l}\text { Total members } \\
\text { per branch }(n)\end{array}$ \\
\hline 1 & Papua & 2 & 2 \\
\hline 2 & Maluku & 1 & 1 \\
\hline 3 & Mataram & 2 & 8 \\
\hline 4 & Manado & 2 & 9 \\
\hline 5 & Makassar & 2 & 18 \\
\hline 6 & Denpasar & 7 & 21 \\
\hline 7 & Samarinda & 5 & 11 \\
\hline 8 & Banjarmasin & 5 & 6 \\
\hline 9 & Kalimantan Barat & 2 & 7 \\
\hline 10 & Surabaya & 21 & 70 \\
\hline 11 & Malang & 5 & 12 \\
\hline 12 & Surakarta & 5 & 25 \\
\hline 13 & Semarang & 8 & 32 \\
\hline 14 & Yogyakarta & 9 & 28 \\
\hline 15 & Bandung & 32 & 37 \\
\hline 16 & Jakarta & 53 & 159 \\
\hline 17 & Lampung & 3 & 8 \\
\hline 18 & Padang & 5 & 13 \\
\hline 19 & Pekanbaru & 11 & 23 \\
\hline 20 & Palembang & 6 & 24 \\
\hline 21 & Medan & 9 & 40 \\
\hline \multirow[t]{2}{*}{22} & Banda Aceh & 5 & 15 \\
\hline & Total & 200 & 569 \\
\hline
\end{tabular}

ISDE, Indonesian Society for Digestive Endoscopy.
(63.5\%), and duration of consultations (44.0\%). All participants reported changes in the inpatient setting of CGE practice. Teleconsultation was more frequently used in the outpatient setting than in the inpatient setting (40.0\% vs. $14.5 \%)$. Difficulties in performing clinical research were reported by $70.5 \%$ of the participants in the study.

\section{Modifications to GIE practice}

The modifications to GIE practice patterns are shown in Table 4. In this study, all participants reported changes in GIE practice patterns, with more than half $(56.5 \%)$ ceasing their GIE practice. The indications for GIE during the study were upper gastrointestinal bleeding (73.5\%), gastrointestinal symptoms with alarm signs $(60.5 \%)$, and lower gastrointestinal bleeding (57.5\%).

We also evaluated the use of PPE during GIE. Face shield was the most frequently used PPE during upper GIE. Furthermore, $56.0 \%$ of the participants wore coveralls and $70.0 \%$ wore an N95 mask during upper GIE. During lower GIE, most participants $(89.0 \%)$ wore a face shield, $33.0 \%$ wore coveralls, and $52.0 \%$ wore an N95 mask.

\section{Physician risk identification}

The investigation of physician risk identification is shown in Table 5. Most participants (86.0\%) worked in high-risk zones. More than one-third of the participants reported inadequate PPE for daily practice.

\section{Participants' involvement in the management of COVID-19}

The majority $(60 \%)$ of the participants worked at a referral hospital. The workplaces of most participants $(n=186,93.0 \%)$ had a local taskforce for COVID-19. As shown in Table 6, the participants' involvement in the management of COVID-19 constituted serving a role in a physician team for COVID-19 (68.5\%) and in a taskforce for COVID-19 at any level (98.0\%).

\section{Overall impact of the COVID-19 pandemic on professional practice}

The score of the overall impact of the COVID-19 pandemic on professional practice was 9 (2-10). Nearly one-half of the participants (43.0\%) reported a score of 10 for the overall impact of the pandemic on professional practice. 
Table 2. Baseline Characteristic of the Participants

\begin{tabular}{|c|c|c|c|}
\hline Characteristics & & Frequency $(n)$ & Percent (\%) \\
\hline \multirow[t]{2}{*}{ Age, yr } & $\cdot<60$ & 171 & 85.5 \\
\hline & $\cdot>60$ & 29 & 14.5 \\
\hline \multirow[t]{2}{*}{ Sex } & - Male & 148 & 74.0 \\
\hline & • Female & 52 & 26.0 \\
\hline \multirow[t]{4}{*}{ Competence } & - Consultant of gastroenterology and hepatology & 59 & 29.5 \\
\hline & - Fellow of gastroenterology and hepatology & 15 & 7.5 \\
\hline & - Fellow of pediatric gastroenterology & 1 & 0.5 \\
\hline & - Internal medicine specialist with competence in basic GIE & 125 & 62.5 \\
\hline \multirow{3}{*}{ Work experience, yr } & $\cdot<5$ & 65 & 32.5 \\
\hline & $\cdot 5-10$ & 69 & 34.5 \\
\hline & $\cdot>10$ & 66 & 33.0 \\
\hline \multirow[t]{4}{*}{ Learning source } & • ISDE/ISG/InaASL & 195 & 97.5 \\
\hline & • APAGE & 5 & 2.5 \\
\hline & •ASGE & 2 & 1.0 \\
\hline & $\cdot$ ESGE & 2 & 1.0 \\
\hline \multirow[t]{5}{*}{ Workplace } & - Government teaching hospital & 68 & 34.0 \\
\hline & - Government non-teaching hospital & 41 & 20.5 \\
\hline & - Private teaching hospital & 10 & 5.0 \\
\hline & - Private non-teaching hospital & 79 & 39.5 \\
\hline & - Others & 2 & 1.0 \\
\hline
\end{tabular}

APAGE, Asian Pacific Association of Gastroenterology; ASGE, American Society for Gastrointestinal Endoscopy; ESGE, European Society of Gastrointestinal Endoscopy; GIE, gastrointestinal endoscopy; InaASL, Indonesian Association for the Study of the Liver; ISDE, Indonesian Society for Digestive Endoscopy; ISG, Indonesian Society of Gastroenterology.

Table 3. Modifications to Clinical Gastroenterology Practice during the Study

\begin{tabular}{|c|c|c|c|}
\hline \multicolumn{2}{|c|}{ Patterns of clinical gastroenterology practice } & $\frac{\text { Frequency }(\boldsymbol{n})}{88}$ & $\begin{array}{c}\text { Percent (\%) } \\
44.0\end{array}$ \\
\hline Outpatient setting & $\begin{array}{l}\text { - Reduction of consultation duration } \\
\text { - Reduction of working hours } \\
\text { - Reduction of the number of attended patients } \\
\text { - Restriction of the workplace } \\
\text { - Cessation of face-to-face consultation } \\
\text { - Utilization of teleconsultation via WhatsApp, Telegram, Line, or SMS messaging } \\
\text { - Utilization of teleconsultation via a hospital-recommended application } \\
\text { - No modification }\end{array}$ & $\begin{array}{l}88 \\
140 \\
127 \\
32 \\
18 \\
32 \\
48 \\
9\end{array}$ & $\begin{array}{c}44.0 \\
70.0 \\
63.5 \\
16.0 \\
9.0 \\
16.0 \\
24.0 \\
4.5\end{array}$ \\
\hline Inpatient setting & $\begin{array}{l}\text { - Limitation of visit duration } \\
\text { - Reduction of working days } \\
\text { - Limitation of the number of hospitalized patients } \\
\text { - Limitation of the workplace } \\
\text { - Cessation of visits } \\
\text { - Utilization of teleconsultation via WhatsApp, Telegram, Line, or SMS messaging } \\
\text { - Utilization of teleconsultation via a hospital-recommended application } \\
\text { - No modification }\end{array}$ & $\begin{array}{c}94 \\
45 \\
68 \\
22 \\
15 \\
12 \\
17 \\
0\end{array}$ & $\begin{array}{c}47.0 \\
22.5 \\
34.0 \\
11.0 \\
7.5 \\
6.0 \\
8.5 \\
0\end{array}$ \\
\hline $\begin{array}{l}\text { Difficulty in performing } \\
\text { clinical research }\end{array}$ & $\begin{array}{l}\cdot \text { Yes } \\
\cdot \text { No }\end{array}$ & $\begin{array}{c}141 \\
59\end{array}$ & $\begin{array}{l}70.5 \\
29.5\end{array}$ \\
\hline
\end{tabular}

SMS, short message service. 
Table 4. Modifications to Gastrointestinal Endoscopy Practice during the Study

\begin{tabular}{|c|c|c|c|}
\hline \multirow{2}{*}{$\begin{array}{l}\text { Patterns of GIE practice } \\
\text { Changes in GIE practice patterns }\end{array}$} & & Frequency $(n)$ & Percent (\%) \\
\hline & $\begin{array}{l}\text { - Limitation of GIE duration } \\
\text { - Reduction of working days } \\
\text { - Limitation of the number of attended patients } \\
\text { - Partial cessation of elective GIE } \\
\text { - Cessation of all GIE } \\
\text { - No modification }\end{array}$ & $\begin{array}{c}13 \\
26 \\
71 \\
47 \\
113 \\
0\end{array}$ & $\begin{array}{c}6.5 \\
13.0 \\
35.5 \\
23.5 \\
56.5 \\
0\end{array}$ \\
\hline Indications of GIE during the study & $\begin{array}{l}\text { - Gastrointestinal symptom(s) without alarm sign(s) } \\
\text { - Gastrointestinal symptom(s) with alarm sign(s) } \\
\text { - Upper gastrointestinal obstruction } \\
\text { - Lower gastrointestinal obstruction } \\
\text { - Screening for colorectal cancer } \\
\text { - Cancer staging } \\
\text { - Polypectomy } \\
\text { - Screening for hepatocellular carcinoma or liver cirrhosis } \\
\text { - Hematemesis and/or melena } \\
\text { - Hematochezia } \\
\text { - Obstructive jaundice }\end{array}$ & $\begin{array}{c}11 \\
121 \\
49 \\
44 \\
20 \\
3 \\
7 \\
45 \\
147 \\
115 \\
25\end{array}$ & $\begin{array}{c}5.5 \\
60.5 \\
24.5 \\
22.0 \\
10.0 \\
1.5 \\
3.5 \\
22.5 \\
73.5 \\
57.5 \\
12.5\end{array}$ \\
\hline PPE during upper GIE & $\begin{array}{l}\text { - Face shield } \\
\text { - Head cap } \\
\text { - Goggles } \\
\text { - N95 mask } \\
\text { - Surgical mask } \\
\text { - Coveralls } \\
\text { - Surgical gown } \\
\text { - Double gloves } \\
\text { - Single glove } \\
\text { - Boot } \\
\text { - Shoe cover }\end{array}$ & $\begin{array}{c}195 \\
162 \\
129 \\
140 \\
115 \\
96 \\
112 \\
137 \\
45 \\
164 \\
67\end{array}$ & $\begin{array}{l}97.5 \\
81.0 \\
64.5 \\
70.0 \\
57.5 \\
48.0 \\
56.0 \\
68.5 \\
22.5 \\
82.0 \\
33.5\end{array}$ \\
\hline PPE during lower GIE & $\begin{array}{l}\text { - Face shield } \\
\text { - Head cap } \\
\text { - Goggles } \\
\text { - N95 mask } \\
\text { - Surgical mask } \\
\text { - Coveralls } \\
\text { - Surgical gown } \\
\text { - Double gloves } \\
\text { - Single glove } \\
\text { - Boot } \\
\text { - Shoe cover }\end{array}$ & $\begin{array}{c}178 \\
158 \\
115 \\
104 \\
91 \\
66 \\
82 \\
104 \\
23 \\
85 \\
44\end{array}$ & $\begin{array}{l}89.0 \\
79.0 \\
57.5 \\
52.0 \\
45.5 \\
33.0 \\
41.0 \\
52.0 \\
11.5 \\
42.5 \\
22.0\end{array}$ \\
\hline Modification in GIE unit staff & $\begin{array}{l}\cdot \text { Yes } \\
\cdot \text { No }\end{array}$ & $\begin{array}{c}28 \\
172\end{array}$ & $\begin{array}{l}14.0 \\
86.0\end{array}$ \\
\hline
\end{tabular}

GIE, gastrointestinal endoscopy; PPE, protective personal equipment. 
Table 5. Physician Risk Identification

\begin{tabular}{|c|c|c|c|}
\hline Risk identification & & Frequency $(n)$ & Percent $(\%)$ \\
\hline Risk identification according to symptom(s) & $\begin{array}{l}\cdot \text { - Yes } \\
\cdot \text { - No }\end{array}$ & $\begin{array}{c}3 \\
197\end{array}$ & $\begin{array}{c}1.5 \\
98.5\end{array}$ \\
\hline Risk identification according to contact history & $\begin{array}{l}\cdot \text { Yes } \\
\cdot \text { No }\end{array}$ & $\begin{array}{c}15 \\
185\end{array}$ & $\begin{array}{c}7.5 \\
92.5\end{array}$ \\
\hline Risk identification according to travel history & $\begin{array}{l}\cdot \text { Yes } \\
\cdot \text { No }\end{array}$ & $\begin{array}{c}43 \\
157\end{array}$ & $\begin{array}{l}21.5 \\
78.5\end{array}$ \\
\hline Risk identification according to exposure to high-risk zones & $\begin{array}{l}\cdot \text { Yes } \\
\cdot \text { - No }\end{array}$ & $\begin{array}{c}172 \\
28\end{array}$ & $\begin{array}{l}86.0 \\
14.0\end{array}$ \\
\hline Self-detection with antibody-based testing & $\begin{array}{l}\cdot \text { Yes } \\
\cdot \text { - No }\end{array}$ & $\begin{array}{c}127 \\
73\end{array}$ & $\begin{array}{l}63.5 \\
36.5\end{array}$ \\
\hline Self-detection with RT-PCR-based testing & $\begin{array}{l}\cdot \text { Yes } \\
\cdot \text { - No }\end{array}$ & $\begin{array}{c}59 \\
141\end{array}$ & $\begin{array}{l}29.5 \\
70.5\end{array}$ \\
\hline Availability of adequate PPE & $\begin{array}{l}\cdot \text { Yes } \\
\cdot \text { - No }\end{array}$ & $\begin{array}{c}132 \\
68\end{array}$ & $\begin{array}{l}66.0 \\
34.0\end{array}$ \\
\hline Performing GIE on suspected/confirmed COVID-19 patients & $\begin{array}{l}\cdot \text { Yes } \\
\cdot \text { - No }\end{array}$ & $\begin{array}{c}15 \\
185\end{array}$ & $\begin{array}{c}7.5 \\
92.5\end{array}$ \\
\hline
\end{tabular}

COVID-19, coronavirus disease 2019; GIE, gastrointestinal endoscopy; PPE, protective personal equipment; RT-PCR, reverse transcriptase polymerase chain reaction.

Table 6. Participants' Involvement in the Management of Coronavirus Disease 2019

\begin{tabular}{llcc}
\hline Type of involvement & Frequency $(\boldsymbol{n})$ & Percent $(\%)$ \\
\hline COVID-19 physician team & $\cdot$ Yes & 137 & 68.5 \\
& $\cdot$ No & 63 & 31.5 \\
COVID-19 task force & $\cdot$ Yes (taskforce at a hospital) & 107 & 53.5 \\
& $\cdot$ Yes (task force in a professional organization) & 90 & 45.0 \\
& $\cdot$ Yes (government task force) & 3 & 1.5 \\
& $\cdot$ No & 4 & 2.0 \\
\hline
\end{tabular}

COVID-19, coronavirus disease 2019.

\section{DISCUSSION}

The COVID-19 pandemic has placed a high level of burden on health-care systems in every country worldwide. The challenge involves delivering high-risk health-care services with a small number of evidence-based medicine options and limited facilities. This issue has threatened health-care systems in terms of the provision of safe and effective health-care services. In the field of gastroenterology, the pandemic has led some professional organizations to introduce guidelines or recommendations on modifications to CGE and GIE practices. This study demonstrated that the COVID-19 pandemic has had a considerable overall impact on physicians practicing CGE and GIE in Indonesia.

The response rate of the survey based on the number of participants was $35.14 \%$. However, as the response rate based on ISDE regional branches was $100 \%$, we concluded that the survey provided representative data on the status of CGE and GIE practices in Indonesia.

This study found a high number of modifications to CGE practice. Most physicians made changes in the outpatient setting, including reducing the working hours, limiting the number of attended patients, and limiting the duration of consultations. Furthermore, all physicians made changes in 
the inpatient setting, including limiting the duration of visits, limiting the number of hospitalized patients, and reducing the number of working days. We also noted that telemedicine, especially teleconsultation, was one of the methods used for delivering a modified CGE service during the COVID-19 pandemic. Forbes et al. ${ }^{11}$ reported similar strategies for changes in CGE practice in response to the COVID-19 pandemic. They also demonstrated that implementing telemedicine was the most favorable method in CGE practice. Furthermore, Shah et al. ${ }^{8}$ suggested telemedicine as a solution for CGE practice issues in an outpatient setting. The challenge of telemedicine is its unavailability and the lack of experience of CGE practitioners, especially in health-care facilities with limited resources.

Owing to the risks of human-to-human transmission and AGP-related transmission, GIE practice has had to undergo considerable revisions during the COVID-19 pandemic. All physicians in this study had made changes to their GIE practice, and more than half of them ceased performing GIE during the pandemic. Forbes et al. ${ }^{11}$ reported that approximately one-quarter of health-care institutions in North America continued performing GIE at normal volumes. Some guidelines recommended limiting GIE practice with strategies to address safety issues for patients and the endoscopy unit staff. ${ }^{12-15}$ The restriction of GIE practice by limiting the indications is highly recommended during the COVID-19 pandemic. $2,5,6,9,12,14-16$ In this study, the most frequent indications for GIE during the pandemic were upper gastrointestinal bleeding, gastrointestinal symptoms with alarm signs, and lower gastrointestinal bleeding. Galloro et al..$^{15}$ noted that during the COVID-19 pandemic, GIE was indicated only for emergency situations (acute gastrointestinal bleeding, foreign body extraction, acute suppurative cholangitis) and cancer care.

In this study, more than one-third of physicians reported a lack of adequate PPE. Additionally, a respirator face mask was not generally reported to be used in upper and lower GIE practice. Appropriate PPE, comprising a face mask, goggles and/or a face shield, a head cap, a surgical gown, and gloves, should be available for all staff members involved in performing GIE. ${ }^{2,5,6,9,12,14-16}$ This precaution aims to reduce exposure to hazards or the transmission risk. Furthermore, the British Society of Gastroenterology emphasized that procedure deferral is necessary until appropriate PPE is available. ${ }^{9}$ A respirator face mask is one of the most important pieces of PPE in GIE practice. Some studies have recommended the use of an N95 face mask to achieve extremely efficient filtration of airborne particles to prevent COVID-19 transmission. ${ }^{2,5,6,9,12,14-16}$

Physician risk identification is essential in performing safe health-care practices during the pandemic. This study demon- strated that physicians practicing CGE and GIE mostly work in high-risk zones. Self-detection of infection, notably with reverse transcriptase polymerase chain reaction-based testing, seemingly indicated a limited coverage of risk mitigation for physicians. The preparedness of a GIE unit for patients with suspected or confirmed COVID-19 is an important issue. Only $7.5 \%$ of the GIE units in this study were prepared for performing GIE on suspected or confirmed COVID-19 patients, whereas the availability of adequate PPE was reported in only $66.0 \%$ of the GIE units. These conditions demonstrated that physicians practicing CGE and GIE in Indonesia are working in high-risk settings.

The limitations of this study included the fact that the online survey format contributed to potential recall bias and was dependent on the participants' honest responses. Moreover, we conducted this cross-sectional study during a relatively short period, and the small number of participants might limit the generalization of the results.

This study showed that the COVID-19 pandemic has had a considerable impact on CGE and GIE practices in Indonesia. Physicians practicing CGE and GIE in Indonesia are working in high-risk settings. Modifications to related clinical practice are necessary to provide health-care services while ensuring the safety of both patients and physicians during procedures. Most physicians in this study directly participated in the management of COVID-19 and were involved in a taskforce for COVID-19 at any level. Further studies are needed to investigate and stimulate innovations in CGE and GIE practices.

Conflicts of Interest

The authors have no potential conflicts of interest.

Funding

None.

Acknowledgments

The authors thank Shinta and Nuvia for their assistance, and the Indonesian Society of Digestive Endoscopy for their collaboration and cooperation in the enrollment of participants.

\section{Author Contributions}

Conceptualization: Ahmad Fariz Malvi Zamzam Zein, Rabbinu Rangga Pribadi, Muhammad Begawan Bestari, Ari Fahrial Syam

Data curation: Uswatun Khasanah

Formal analysis: AFMZZ, RRP, UK

Funding acquisition: AFMZZ

Investigation: AFMZZ, RRP, UK

Methodology: UK

Project administration: AFMZZ, RRP

Resources: AFMZZ, RRP

Software: UK

Supervision: AFMZZ, MBB, AFS

Validation: RRP, UK

Visualization: RRP 
Writing-original draft: AFMZZ, RRP, UK

Writing-review\&editing: AFMZZ, RRP, UK, MBB, AFS

ORCID

Ahmad Fariz Malvi Zamzam Zein: https://orcid.org/0000-0001-7821-3813 Rabbinu Rangga Pribadi:

Uswatun Khasanah:

Muhammad Begawan Bestari:

Ari Fahrial Syam: https://orcid.org/0000-0001-8450-4887 https://orcid.org/0000-0002-3320-3993 https://orcid.org/0000-0002-6911-8213 https://orcid.org/0000-0003-0041-3553

\section{REFERENCES}

1. Tang D, Comish P, Kang R. The hallmarks of COVID-19 disease. PLoS Pathog 2020;16:e1008536.

2. Libânio D, Bastos P, Pimentel-Nunes P. Safe and valuable endoscopy in the COVID era. GE Port J Gastroenterol 2020;27:219-223.

3. Tse F, Borgaonkar M, Leontiadis GI. COVID-19: advice from the Canadian Association of Gastroenterology for endoscopy facilities, as of March 16, 2020. J Can Assoc Gastroenterol 2020;3:147-149.

4. Onoyama T, Isomoto H. COVID-19 and gastrointestinal endoscopy: Importance of reducing SARS-CoV-2 infection risks of medical workers and preserving personal protective equipment resources. Dig Endosc 2020;32:732-735.

5. Perisetti A, Gajendran M, Boregowda U, Bansal P, Goyal H. COVID-19 and gastrointestinal endoscopies: current insights and emergent strategies. Dig Endosc 2020;32:715-722.

6. Ang TL. Gastrointestinal endoscopy during COVID-19 pandemic. J Gastroenterol Hepatol 2020;35:701-702.

7. Soetikno R, Teoh AYB, Kaltenbach T, et al. Considerations in performing endoscopy during the COVID-19 pandemic. Gastrointest Endosc 2020;92:176-183.
8. Shah R, Satyavada S, Ismail M, et al. COVID-19 pandemic through the lens of a gastroenterology fellow: looking for the silver lining. Gastrointest Endosc 2020;92:394-398.

9. Penman I, Edwards C, McKinlay A. BSG guidance on recommencing GI endoscopy in the deceleration \& early recovery phases of the COVID-19 pandemic [Internet]. London: British Society of Gastroenterology; c2020 [updated 2020 Jun 3]. Available from: https://www.bsg.org.uk/ covid-19-advice/bsg-guidance-on-recommencing-gi-endoscopy-in-thedeceleration-early-recovery-phases-of-the-covid-19-pandemic/.

10. Castro Filho EC, Castro R, Fernandes FF, Pereira G, Perazzo H. Gastrointestinal endoscopy during the COVID-19 pandemic: an updated review of guidelines and statements from international and national societies. Gastrointest Endosc 2020;92:440-445.e6.

11. Forbes N, Smith ZL, Spitzer RL, Keswani RN, Wani SB, Elmunzer BJ. Changes in gastroenterology and endoscopy practices in response to the coronavirus disease 2019 pandemic: results from a North American survey. Gastroenterology 2020;159:772-774.e13.

12. Gralnek IM, Hassan C, Beilenhoff U, et al. ESGE and ESGENA position statement on gastrointestinal endoscopy and the COVID-19 pandemic. Endoscopy 2020;52:483-490.

13. Penman I, Edwards C, Coleman M, McKinlay A. Endoscopy activity and COVID-19: BSG and JAG guidance [Internet]. London: British Society of Gastroenterology; c2020 [updated 2020 Apr 3]. Available from: https://www.bsg.org.uk/covid-19-advice/endoscopy-activity-and-covid19-bsg-and-jag-guidance/.

14. Repici A, Maselli R, Colombo M, et al. Coronavirus (COVID-19) outbreak: what the department of endoscopy should know. Gastrointest Endosc 2020;92:192-197.

15. Galloro G, Pisani A, Zagari RM, et al. Safety in digestive endoscopy procedures in the covid era recommendations in progres of the italian society of digestive endoscopy. Dig Liver Dis 2020;52:800-807.

16. Liu XY, Cai MY, Wang P, Zhou PH. How to manage an endoscopy unit during a COVID-19 pandemic. VideoGIE 2020;5:229. 